\title{
COMPARTIMENTOS DE RELEVO DA PRAIA DE PONTA DO MEL - LITORAL SETENTRIONAL DO ESTADO DO RIO GRANDE DO NORTE, BRASIL
}

\author{
Joyce Clara Vieira Ferreira ${ }^{(a)}$, Cleanto Carlos Lima da Silva ${ }^{(b)}$, Zuleide Maria Carvalho \\ Lima $^{(\mathrm{c})}$, Moacir Paulo de Souza ${ }^{(\mathrm{d})}$ \\ (a) Departamento de Geografia, UFRN, joyceclara@hotmail.com \\ (b) Departamento de Geografia, UFRN, cleantocarlos13@gmail.com \\ (c) Departamento de Geografia, UFRN, zuleide@ufrnet.br \\ (d) Departamento de Geografia, moanatal@ hotmail.com
}

\section{EIXO: SISTEMAS GEOMORFOLÓGICOS: ESTRUTURA, DINÂMICAS E PROCESSOS}

\section{Resumo}

O presente artigo tem por objetivos identificar e caracterizar os compartimentos de relevo da praia de Ponta do Mel localizada no litoral setentrional do estado do Rio Grande do Norte, Nordeste do Brasil. Para tanto, utilizamos como base metodológica a compartimentação topográfica de Ab'sáber (1969) e a classificação taxonômica de Ross (2009, 2011 e 2012). Como resultado da análise da paisagem da praia de Ponta do Mel, perceberam-se duas unidades morfoesculturais: a planície praial e o tabuleiro costeiro semiárido, ambos inseridos na unidade morfoestrutural bacia sedimentar da margem continental passiva Potiguar. Foram percebidos, também, tipos de formas de relevo em cada unidade, além das vertentes e das formas de processos atuais.

Palavras chaves: compartimentação do relevo, praia de Ponta do Mel, Rio Grande do Norte.

\section{Introdução}

Os estudos voltados para o ambiente costeiro são de grande valia no tocante ao planejamento e gestão destas áreas, uma vez que nelas se encontra a maior concentração populacional do planeta. Considerando a importância dos estudos litorâneos para um estado como o Rio Grande do Norte que explora em demasia o uso e a ocupação antrópica de suas praias, este artigo tem por objetivos identificar e caracterizar os compartimentos de relevo presentes na paisagem da praia de Ponta do Mel. Entende-se que através da compartimentação do relevo, se torna possível apreender as dinâmicas e as interações dos sistemas contidos na paisagem em foco, para tanto se utilizou como referência metodológica o primeiro nível de tratamento para pesquisas geomorfológicas sugerido por Ab’Sáber (1969). De acordo com o autor, os estudos que contemplam a geomorfologia devem abordar a compartimentação do relevo da área a ser estudada para o entendimento da paisagem.

Segundo Casseti (2005) a compartimentação do relevo demonstra o resultado das relações processuais e respectivas implicações tectônico-estruturais que foram registradas ao longo do tempo, tendo em conta as mudanças climáticas capazes de gerar modelados diferenciados. Desse modo, dividiu-se a área de estudo (praia de Ponta do Mel) em compartimentos topográficos fazendo uso, também, da análise taxonômica sugerida por Ross (2009, 2011 e 2012). 
XVII Simpósio Brasileiro

de Geografia Física Aplicada

I Congresso Nacional

de Geografia Física
OS DESAFIOS DA GEOGRAFIA FÍSICA NA FRONTEIRA DO CONHECIMENTO

Instituto de Geociências - Unicamp

Campinas - SP

28 de Junho à 02 de Julho de 2017

\section{Metodologia}

O estudo da compartimentação do relevo contribui para o entendimento das paisagens, pois auxilia na compreensão das dinâmicas que as permeiam. Conforme Ab'Sáber (1969), as análises que contemplam a geomorfologia devem abordar a compartimentação do relevo, buscando "homogeneizar, compatibilizar e sistematizar as informações de um determinado trecho costeiro, facilitando o seu gerenciamento e integração" (TESSLER E GOYA, 2005, P. 16), sendo, portanto, de grande relevância no tocante ao planejamento e gestão das áreas costeiras.

Para tanto, a proposta de Ross (2011) contribui nesse sentido e atenta que o relevo deve ser subdividido em táxons, considerados pelo autor como os tamanhos diferenciados das formas de relevo, constituídos por diferentes idades e processos genéticos interrelacionados e interdependentes aos demais componentes presentes na natureza. Dessa maneira, dividiu-se a praia de Ponta do Mel em compartimentos geomorfológicos com base na análise taxonômica proposta por Ross (2011).

Ross (2009, 2011 e 2012) embasado nos trabalhos de Penck (1953), Demek (1967) e Mescherikov (1968) e no Radambrasil (1981) aponta para uma subdivisão em seis ordens taxonômicas, que podem ser analisadas da seguinte perspectiva:

$1^{\circ}$ Táxon - Unidades Morfoestruturais: considerado como o táxon maior, corresponde às macroestruturas geológicas. De acordo com IBGE (2009) os domínios morfoestruturais são áreas que apresentam as mesmas características morfoestruturais, ou seja, apresentam a mesma constituição litológica, orientação e o direcionamento das lineações estruturais, concentração de corpos intrusivos, relações dos padrões e a hierarquia da drenagem, bem como, a litoestrutura e as relações desta com os diversos tipos de modelados.

$2^{\circ}$ Táxon - Unidades Morfoesculturais: possuem sua gênese pautada na alteração climática temporal, sendo consideradas como subunidades do relevo morfoestrutural, se diferenciando pelos diferentes níveis topográficos.

$3^{\circ}$ Táxon - Padrões de Formas Semelhantes (modelado): agrupamentos de formas de agradação (relevo de acumulação) e de denudação (relevo de dissecação) do relevo com tamanhos menores, onde os processos morfoclimáticos atuais começam a ser facilmente notados, podendo ser representados pelas letras A e D, respectivamente. Neste nível de mapeamento o destaque é para o conjunto de feições de relevo que apresentem distinção e/ou semelhanças entre si.

$4^{\circ}$ Táxon - Conjunto de formas Semelhantes: refere-se às formas de relevo, podendo ser classificadas como de agradação e denudação. Podem ser: formas aguçadas (a), convexas (c), tabulares (t) e 
OS DESAFIOS DA GEOGRAFIA FÍSICA NA FRONTEIRA DO CONHECIMENTO

Instituto de Geociências - Unicamp

Campinas - SP

28 de Junho à 02 de Julho de 2017

aplanadas (p), nos relevos de denudação; nos relevos de agradação, tem-se as planícies fluviais (pf) e as planícies lacustres (pfl).

$5^{\circ}$ Táxon - Elementos em Formas de Vertentes (dimensão de formas): são vertentes ou setores das vertentes, consideradas como dimensões menores do relevo, que pertencem a cada uma das formas individualizadas do relevo, podendo ser dos tipos: convexos, retilíneos, aguçados, planos, abruptos.

$6^{\circ}$ Táxon - Formas de Processos Atuais (formas lineares do relevo): são formas geradas por processos erosivos e acumulativos atuais como as voçorocas, ravinas, deslizamentos, assoreamentos, depósitos aluvionares de inundação, sendo produto de processos morfogenéticos e de ação antrópica.

Tomando como referência essa taxonomia, a análise da declividade do terreno permitiu segregar as feições homogêneas do relevo da praia de Ponta do Mel, subdividindo-as em unidades morfoesculturais geradas pela ação climática ao longo do tempo geológico. Nesse sentido, a imagem SRTM com data de aquisição 19 de janeiro de 2017 (coordenadas: -5.78535,-36.45182), disponibilizadas pelo site do Serviço Geológico Americano - USGS (2017) foi relevante para as primeiras análises morfológicas da praia.

Faar et al (2007), destaca que a missão SRTM - Shuttle Radar Topography Mission - teve o objetivo de adquirir uma base de dados sobre a topografia da Terra. Primeiramente, as imagens possuíam resolução de 90m, hoje, após a missão ocorrida em 2000 com parceria do serviço espacial da Alemanha, houve uma melhoria das imagens chegando a $30 \mathrm{~m}$ de resolução. Desse modo, perceberam-se em Ponta do Mel duas unidades morfoesculturais: a planície praial e o tabuleiro costeiro semiárido, ambos inseridos na unidade morfoestrutural bacia sedimentar da margem continental passiva Potiguar. Essas unidades são separadas pelos desníveis das falésias que fazem parte da paisagem deste litoral.

Tomando como base o que foi explicitado, entende-se que cada unidade morfoescultural foi gerada por processos climáticos diferenciados ao longo do tempo geológico, entretanto, as unidades morfoesculturais podem compor a paisagem de um mesmo domínio morfoclimático atual, o que ratifica a ideia de Ross (2011) de que as unidades morfoesculturais não possuem relação genética com as características climáticas atuais e, além disso, podem ser subdivididas por meio de diferentes níveis topográficos (ROSS, 2012).

Para o mapeamento, foram utilizados como referências o banco de dados da CPRM (2006) e do IDEMA (2006), além de imagens disponibilizadas pelo Google Earth Pro, referente ao ano de 2017, as quais foram georreferenciadas no datum SIRGAS 2000 zona 24 com auxílio da plataforma digital Arcgis 10.3 versão Trial. Por fim, após a elaboração do mapa de compartimentação da praia de Ponta do Mel, foi realizada a caracterização desses compartimentos de relevo, considerando os aspectos 
XVII Simpósio Brasileiro

de Geografia Fisica Aplicada

I Congresso Nacional

de Geografia Física
OS DESAFIOS DA GEOGRAFIA FÍSICA NA FRONTEIRA DO CONHECIMENTO

Instituto de Geociências - Unicamp

Campinas - SP

28 de Junho à 02 de Julho de 2017

geológicos, geomorfológicos, pedológicos, climáticos e da vegetação, além de atentar para as intervenções antrópicas contidas nas áreas de estudo, fazendo uso da literatura disponível e de visitas de campo.

\section{Compartimentação Litorânea}

Diniz e Oliveira (2016) atentam que as primeiras tentativas de compartimentação do litoral do Brasil datam de 1916 e 1927 através dos trabalhos de Gabaglia e Carvalho, respectivamente. A primeira compartimentação analisou as informações até então disponíveis sobre o litoral brasileiro, enquanto que a segunda proposta pautou-se apenas nos aspectos tectônicos como elemento de classificação.

De acordo com Tessler e Goya (2005) e Diniz e Oliveira (2016), o primeiro trabalho sobre a macrocompartimentação morfológica da costa brasileira mais completa e que considerou a variável clima associada às propostas anteriores, foi realizada por Silveira (1964). Nesta ocasião, o autor subdividiu o litoral brasileiro em cinco grandes compartimentos: Litoral Amazônico, Litoral Nordestino de Barreiras, Litoral Oriental, Litoral Sudeste ou de Escarpas Cristalinas e Litoral Meridional ou Subtropical. Nesta proposta, a área de abrangência correspondente à praia de Ponta do Mel insere-se no compartimento denominado de Litoral Nordestino de Barreiras.

Diante disso, Muehe e Nicolodi (2008) sugeriram uma revisão da classificação proposta por Silveira (1964) na qual atingiram como resultado "a identificação de maior número de macrocompartimentos e ampliação de sua abrangência, com a inclusão da plataforma continental interna. " (MUEHE E NICOLODI, 2008, p.23). Nesta compartimentação, a praia de Ponta do Mel encontra-se na Costa Semi-Árida Sul, delimitada entre o Cabo do Calcanhar, localizado no estado do Rio Grande do Norte, e a Ponta do Itapagé, situada no estado do Ceará.

Em uma análise mais recente, Diniz e Oliveira (2016) trabalharam em uma compartimentação voltada para o litoral nordestino, considerando duas regiões litorâneas: a Costa Semiárida Brasileira e a Costa dos Recifes. Para delimitação destas regiões os autores analisaram a orientação geral da linha de costa, os aspectos geológico-geomorfológicos, o tipo climático predominante e os aspectos oceanográficos.

Em seguida, foram delimitados os compartimentos contidos nessas regiões (Costa Semiárida Brasileira e a Costa dos Recifes), tomando como base os seguintes aspectos: geometria da linha de costa; geologia; geomorfologia; subtipos climáticos e; oceanografia. Diante disso, percebeu-se que a praia de Ponta do Mel insere-se na Costa Semiárida brasileira no compartimento denominado Costa Branca.

Outra contribuição que merece destaque consiste no trabalho de Vital et al (2006), pois organizaram uma proposta de compartimentação de relevo para zona litorânea com ênfase no estado do Rio Grande do Norte. O resultado desse estudo consistiu no total de 52 compartimentos geomorfológicos embasados na resposta morfodinâmica e nas principais feições morfológicas do relevo praial. Neste esforço de classificação destaca-se a inserção da praia de Areia Branca inserida no compartimento 46- 
XVII Simpósio Brasileiro

de Geografia Fisica Aplicada

I Congresso Nacional

de Geografia Física
OS DESAFIOS DA GEOGRAFIA FÍSICA NA FRONTEIRA DO CONHECIMENTO

Instituto de Geociências - Unicamp

Campinas - SP

28 de Junho à 02 de Julho de 2017

47 (Ib-IIe-IIIa-E) denominado de Praia exposta com falésia viva e campos de dunas barcanas e barcanóides.

Diante do exposto, observam-se o desempenho desses autores no tocante às classificações do litoral brasileiro em diferentes escalas de mapeamento. Destarte, para este artigo, foi realizada a compartimentação do relevo praial, conforme sugerido por Ab'Sáber (1969) e Ross (2009, 2011 e 2012) contemplando a praia de Ponta do Mel situadas no litoral setentrional do estado do Rio Grande do Norte.

Como foi explicitado, foram delimitadas duas unidades morfoesculturais: a planície praial e o tabuleiro costeiro semiárido, ambas separadas pelos desníveis das falésias esculpidas nas rochas sedimentares do Grupo Barreiras que fazem parte da paisagem deste litoral. Nessas unidades morfoesculturais foram identificados "tipos de formas de relevo" que serão descritos a seguir.

\subsection{Tabuleiro costeiro semiárido}

A unidade padrão de formas semelhantes, denominada Tabuleiro costeiro semiárido, compõem a paisagem da praia de Ponta do Mel localizada no litoral setentrional do estado do Rio grande do Norte. O tabuleiro é uma área considerada quase plana e formada por rochas pertencentes ao Grupo Barreiras. Villwock (2005) destaca que os sedimentos encontrados no Grupo Barreiras possuem idade Terciária e foram retrabalhados no Pleistoceno e no Holoceno, dando origem as feições geomorfológicas dos tabuleiros costeiros. Sobre esta unidade observam-se tipos de formas de relevo caracterizados por as dunas móveis, dunas parcialmente cobertas por vegetação e as falésias demarcando a transição para a planície praial (Tabela I e Figura 1).

As dunas móveis estão associadas aos campos de dunas do tipo barcana e barcanoíde, sendo a primeira tipologia caracterizada, conforme Giannini et al (2008), por duas caldas desprovidas de vegetação que se alongam a favor do vento, apresentando tamanho pequeno e rápida mobilidade. A duna barcanoíde possui as mesmas características, todavia se formam mediante a maior disponibilidade de sedimentos, tornando-as maiores. As dunas parcialmente cobertas por vegetação são encontradas em menor proporção neste litoral. A vegetação que se desenvolve é do tipo restinga arbustiva, podendo conter espécies típicas da caatinga.

As falésias também se destacam na paisagem da praia de Ponta do Mel e podem ser consideradas como "um ressalto não coberto pela vegetação, com declividades muito acentuadas e de alturas variadas, localizado na linha de contato entre a terra e o mar" (CHRISTOFOLETTI, 1980, p. 133), onde são consideradas como resultado de movimentos tectônicos. As falésias de Ponta do Mel são vertentes desprovidas de vegetação e com trechos demarcados por processos erosivos, caracterizados por sulcos e ravinas. 
XVII Simpósio Brasileiro de Geografia Fisica Aplicada

I Congresso Nacional de Geografia Física
OS DESAFIOS DA GEOGRAFIA FÍSICA NA FRONTEIRA DO CONHECIMENTO Instituto de Geociências - Unicamp

Campinas - SP

28 de Junho à 02 de Julho de 2017

Tabela I - Compartimentação da praia de Ponta do Mel - RN

\begin{tabular}{|c|c|c|c|c|c|c|c|}
\hline \multicolumn{8}{|c|}{ PRAIA DE PONTA DO MEL - LITORAL SETENTRIONAL DO RIO GRANDE DO NORTE } \\
\hline $\begin{array}{l}\text { Padrões de } \\
\text { formas } \\
\text { semelhantes }\end{array}$ & Morfocronologia & $\begin{array}{c}\text { Tipos de formas } \\
\text { de relevo }\end{array}$ & Geomorfologia & Geologia & Pedologia & Clima & Vegetação \\
\hline \multirow[t]{2}{*}{$\begin{array}{c}\text { Tabuleiro } \\
\text { Costeiro }\end{array}$} & $\begin{array}{c}\text { Período Neógeno } \\
\text { (Plioceno/Mioceno) }\end{array}$ & $\begin{array}{l}\text { 1. Tabuleiro } \\
\text { costeiro } \\
\text { semiárido (Dp) }\end{array}$ & $\begin{array}{l}\text { Superficie suavemente } \\
\text { plana, com drenagens de } \\
\text { baixaransidade } \\
\text { (apresenta formação de } \\
\text { sulcos e ravinamentos) e } \\
\text { vertentes com pouco } \\
\text { declive. Todavia, o limite } \\
\text { dos tabuleiros es } \\
\text { demarcado por falésias. } \\
\text { Esta feição apresenta } \\
\text { terreno bastante } \\
\text { dissecado devido a } \\
\text { ocupação antrópica que } \\
\text { maximiza os processos } \\
\text { intempérico-erosivos. }\end{array}$ & $\begin{array}{|lr|}\text { Composto } & \text { por } \\
\text { rochas } & \\
\text { sedimentares } & \text { do } \\
\text { Grupo } & \text { Barreiras } \\
\text { (arenitos } & \text { com } \\
\text { matriz } & \text { silto- } \\
\text { argilosa). } & \end{array}$ & $\begin{array}{l}\text { Latossolo } \\
\text { vermelho- } \\
\text { amarelo; } \\
\text { Solos Aluviais. }\end{array}$ & Semiárido. & $\begin{array}{c}\text { Savana } \\
\text { estépica } \\
\text { arborizada } \\
\text { ou caatinga } \\
\text { arbustivo- } \\
\text { arbórea. }\end{array}$ \\
\hline & $\begin{array}{c}\text { Periodo Quaternário } \\
\text { (Holoceno / Pleistoceno) }\end{array}$ & 2.Dunas (Ade) & $\begin{array}{l}\text { As dunas estão } \\
\text { sobrepostas aos } \\
\text { tabuleiros e apresentam- } \\
\text { se dos tipos barcana e } \\
\text { barcanoides devido a } \\
\text { intensidade dos ventos e } \\
\text { disponibilidade de } \\
\text { sedimentos desta região. }\end{array}$ & $\begin{array}{lr}\text { As dunas são } \\
\text { compostas por } \\
\text { areias quartzosas } \\
\text { resultantes } & \text { de } \\
\text { processos } & \\
\text { eólicos. }\end{array}$ & $\begin{array}{l}\text { Neossolos } \\
\text { quartzarênico. }\end{array}$ & & $\begin{array}{l}\text { Restinga } \\
\text { arbustiva } \\
\text { (floresta } \\
\text { esclerófila, } \\
\text { escrube } \\
\text { esclerófilo). }\end{array}$ \\
\hline \multirow{3}{*}{ Planicie praial } & \multirow{3}{*}{$\begin{array}{l}\text { Periodo Quatemário } \\
\text { (Holoceno/Pleistoceno) }\end{array}$} & 1.Duna (Ade) & 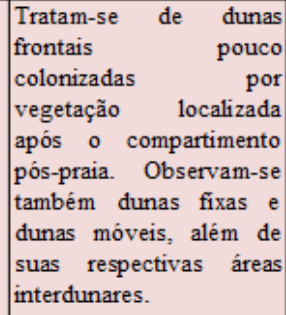 & $\begin{array}{lr}\text { Depósitos r } & \text { de } \\
\text { areias quartzosas } \\
\text { resultantes } & \text { de } \\
\text { processos } & \\
\text { eólicos. }\end{array}$ & $\begin{array}{l}\text { Neossolos } \\
\text { quartzarênico. }\end{array}$ & \multirow{3}{*}{ Semiárido. } & $\begin{array}{l}\text { Restinga } \\
\text { arbustiva } \\
\text { (floresta } \\
\text { esclerófila, } \\
\text { escrube } \\
\text { esclerófilo ). }\end{array}$ \\
\hline & & 2.Praia (Apm) & $\begin{array}{l}\text { Área plana resultante da } \\
\text { combinação de processos } \\
\text { de acumulação marinha, } \\
\text { possui compartimentos } \\
\text { de relevo denominados } \\
\text { pós-praia, estirâncio e } \\
\text { antepraia. }\end{array}$ & 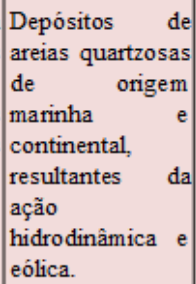 & $\begin{array}{l}\text { Neossolos } \\
\text { quartzarênico. }\end{array}$ & & $\begin{array}{l}\text { Formação } \\
\text { pioneira da } \\
\text { planicie } \\
\text { costeira. }\end{array}$ \\
\hline & & $\begin{array}{l}\text { 3.Arenitos } \\
\text { ferruginosos }\end{array}$ & $\begin{array}{l}\text { Arenitos ferruginosos } \\
\text { derivados de fragmentos } \\
\text { das falésias encontradas } \\
\text { nos tabuleiros costeiros. }\end{array}$ & $\begin{array}{l}\text { Rochas oriundas } \\
\text { da desagregação } \\
\text { do } r \text { Grupo } \\
\text { Barreiras. }\end{array}$ & - & & - \\
\hline
\end{tabular}




\section{OS DESAFIOS DA GEOGRAFIA FÍSICA NA FRONTEIRA DO CONHECIMENTO Instituto de Geociências - Unicamp Campinas - SP \\ 28 de Junho à 02 de Julho de 2017}

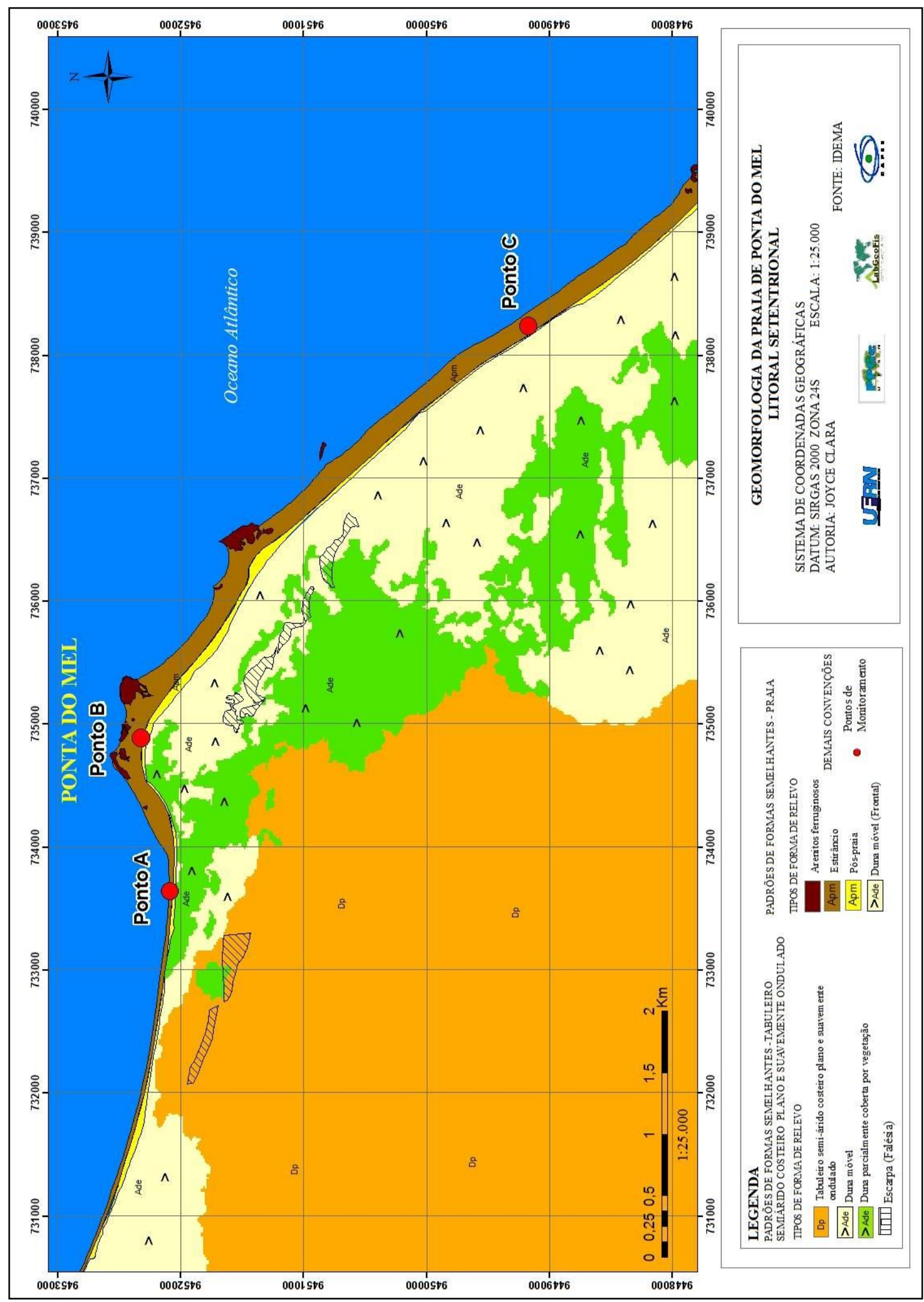

Figura 1 - Mapa de compartimentação geomorfológica da praia de Ponta do Mel. Fonte: IDEMA (2006), CPRM (2006). 


\subsection{Planície praial}

A planície praial é caracterizada como áreas "relativamente planas, baixas, localizadas junto ao mar, e cuja formação resultou de sedimentos marinhos e fluviais" (MUEHE, 2009, p. 287). Nestas áreas, os sedimentos contidos, possuem idades geológicas consideradas recentes, podendo ser enquadrados no período Quaternário. A planície praial de Ponta do Mel é caracterizada pela presença de dunas frontais, arenitos ferruginosos e a praia (pós-praia, estirâncio e antepraia) (Tabela I e Figura 1).

De acordo com Hesp (2002), as dunas frontais são cristas dunares arenosas com vegetação, formadas nos setores mais próximos do mar e podem ser denominadas, também, de dunas embrionárias, crista de retenção, crista de praia, dunas transversais ou cordão de dunas paralelas. Estes tipos de depósitos são encontrados na praia de Ponta do Mel. Os arenitos ferruginosos também estão presentes nesta praia, sendo estes originados através da oxidação de fragmentos de rochas que se desagregam das falésias do tabuleiro costeiro formado, geologicamente, por rochas do Grupo Barreiras.

A praia de Ponta do Mel é demarcada por um compartimento de estirâncio de tamanho superior ao compartimento de pós-praia, sendo este último, em alguns trechos, inexistente. Isso pôde ser percebido em um trabalho de campo realizado no dia 13/01/2017 nesta localidade, tomando como base as informações de marés referentes ao Porto Areia Branca (Termisa) que registrou uma maré baixa de 0.3 $\mathrm{m}$ às 10:58h e maré alta: $3.6 \mathrm{~m}$ às 17:06h. Tal atividade teve o intuito de coletar informações acerca dos aspectos físicos e morfodinâmicos da praia.

A morfodinâmica praial pode ser entendida como "um método de estudo o qual integra observações morfológicas e dinâmicas numa descrição mais completa e coerente da praia e zona de arrebentação" (CALLIARI et al, 2003, p. 63). Para tanto, selecionou-se três pontos de coleta de dados que podem ser visualizados no mapa de compartimentação geomorfológica da praia de Ponta do Mel.

O Ponto A (UTM: $\mathrm{x}=733486 \mathrm{E}$ e y = 9452054 S), localiza-se próximo a um campo de dunas confinado entre a falésia e o compartimento de pós-praia. Nesta localidade foi realizado levantamento topográfico de um perfil praial, onde não consta a presença do compartimento pós-praia e o compartimento de estirâncio possui $58 \mathrm{~m}$ de largura e uma baixa inclinação $\left(3^{\circ}\right)$, como pode ser conferido a seguir (Figura 2 e Figura 3):

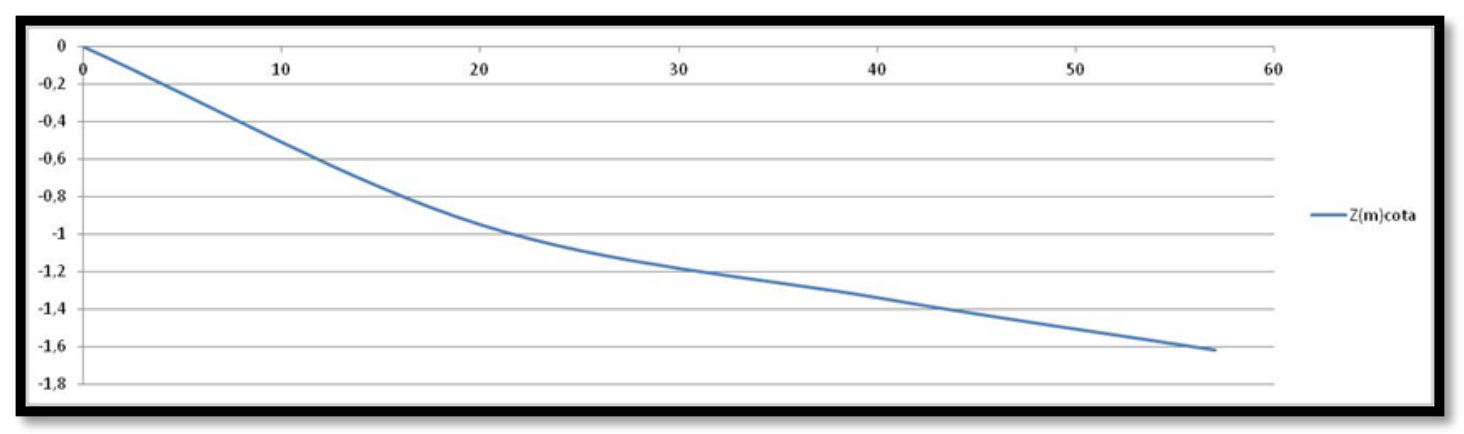

Figura 2 - Perfil praial do Ponto A localizado na praia de Ponta do Mel - Areia Branca/RN. 


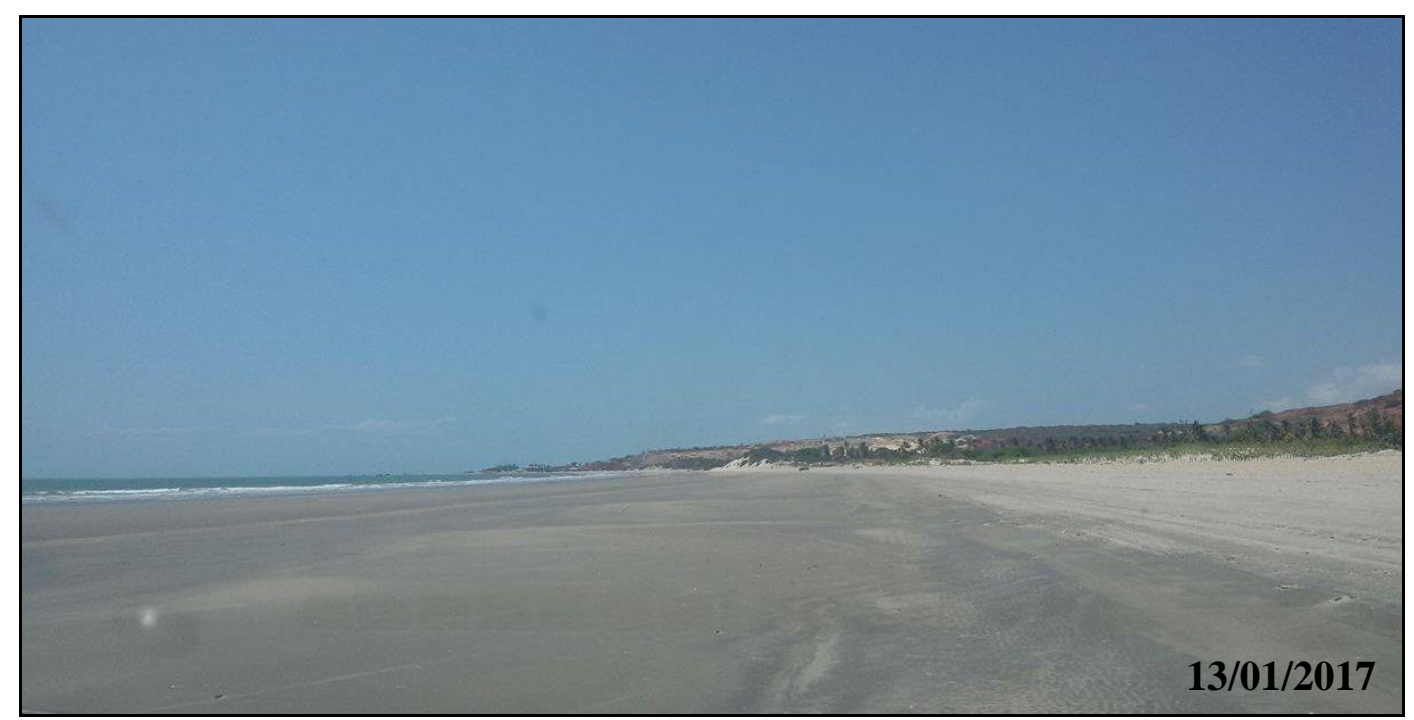

Figura 3 - Paisagem próxima ao Ponto A localizado na praia de Ponta do Mel. Foto: Joyce Clara.

O ponto B (UTM: $\mathrm{x}=734871 \mathrm{E}$ e y $=9452274$ S) está situado em uma área de maior ocupação, uma vez que possui maior número de banhista e estruturas de alvenaria. Parte das barracas, restaurantes e pousadas estão situadas no compartimento pós-praia que registrou $25 \mathrm{~m}$ de largura. Nesta localidade a zona de pós-praia está confinada entre um estirâncio, largo $(106 \mathrm{~m})$ e de baixa inclinação $\left(2^{\circ}\right)$, e uma duna frontal.

Destaca-se como interferência antrópica deste ponto, a ocorrência de lixo e dejetos lançados diretamente na praia, além do trânsito constante de pickups, buggys e quadriciclos a serviço do turismo (Figura 4). No perfil praial coletado (Figura 5) observa-se a presença de uma berma localizada entre $30 \mathrm{~m}$ e $60 \mathrm{~m}$, posteriormente, nota-se um aplanamento do relevo, representando o compartimento de estirâncio quase plano.

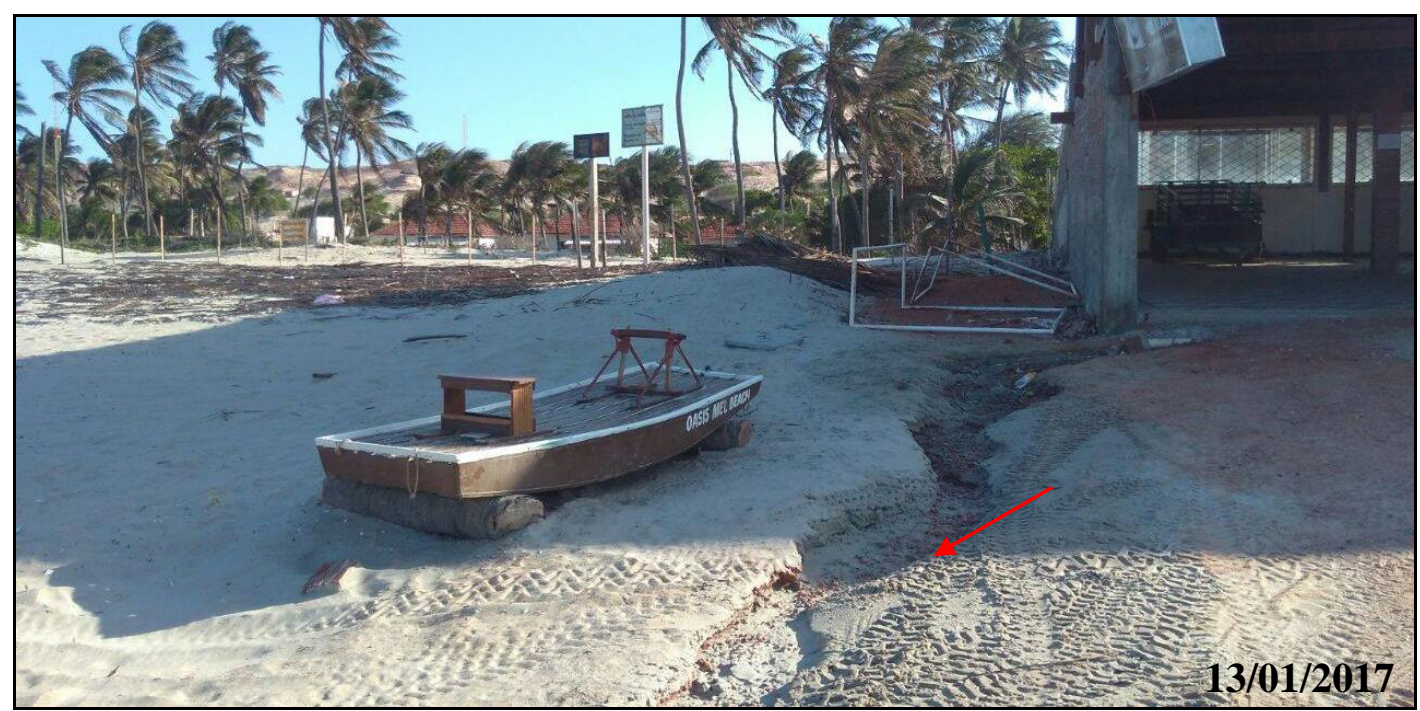

Figura 4 - dejetos sendo lançados no compartimento pós-praia no Ponto B localizado na praia de Ponta do Mel. Foto: Ivaniza Sales. 


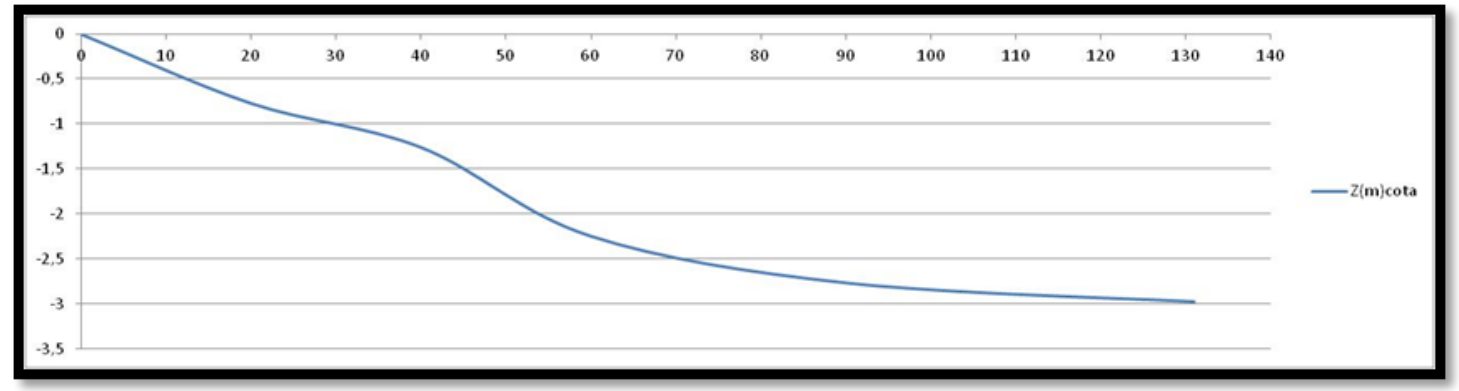

Figura 5 - Perfil praial do Ponto B localizado na praia de Ponta do Mel - Areia Branca/RN.

O ponto C localiza-se na porção sul do mapa de compartimentação sob as coordenadas UTM: $\mathrm{x}=$ $738114 \mathrm{E}$ e y $=9449211 \mathrm{~S}$. Este ponto registrou um compartimento de pós-praia com 1,50 m de largura, limitado entre uma pequena falésia, detentora de algumas marcas de solapamento, e um compartimento de estirâncio contendo $110 \mathrm{~m}$ de largura e inclinação de $2^{\circ}$. O estirâncio desta localidade apresentou carbonatos e um canal por onde a água do mar adentrava, sendo possível observa-lo pelo perfil (Figura 6) no intervalo entre $60 \mathrm{~m}$ e $65 \mathrm{~m}$ (Figura 7).

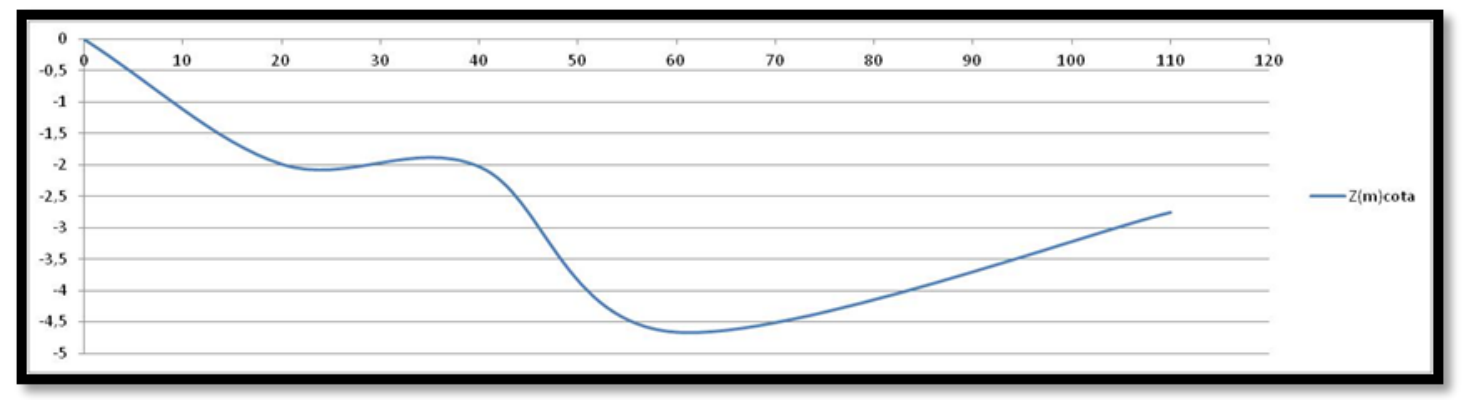

Figura 6 - Perfil praial do Ponto C localizado na praia de Ponta do Mel - Areia Branca/RN.

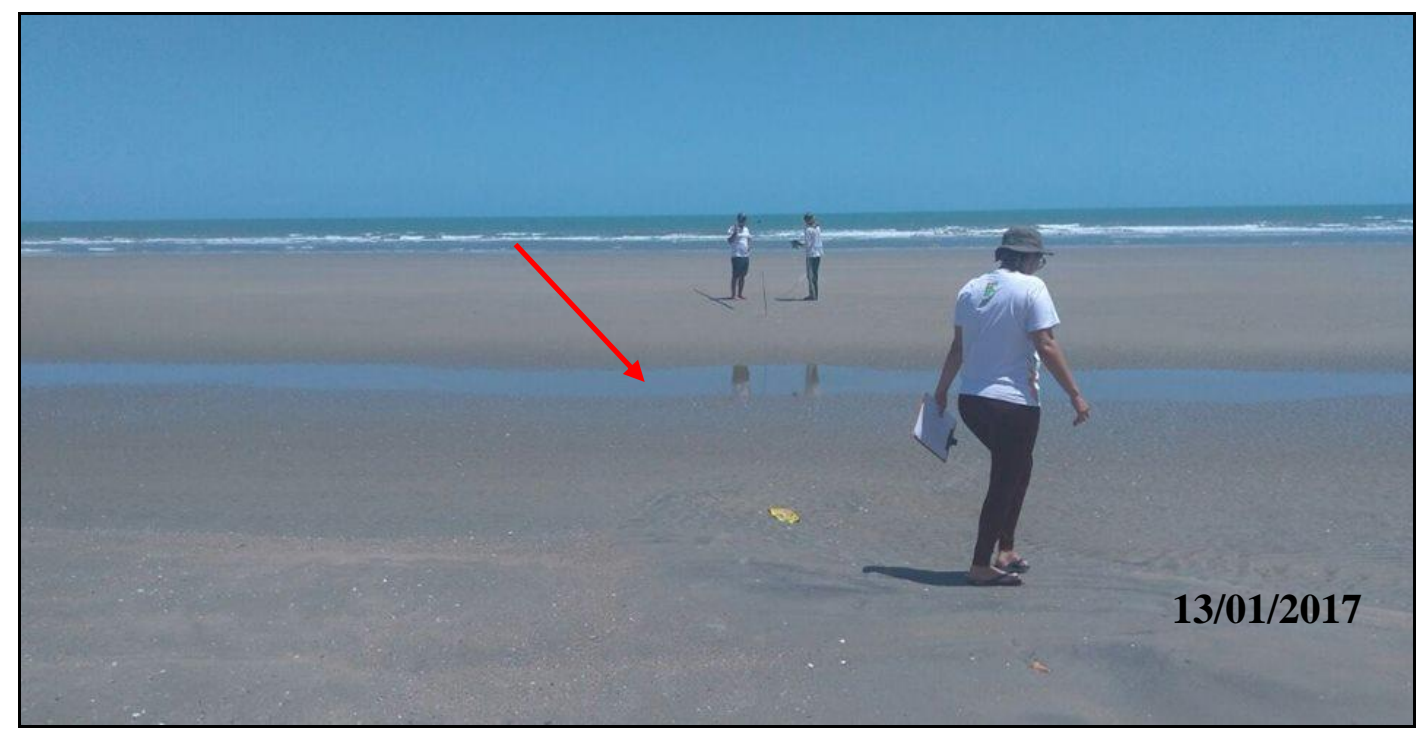

Figura 7 - formação de um canal decorrente da subida da maré. Ponto C - Ponta do Mel. Foto: Ivaniza Sales.

Neste trabalho de campo, também foram coletados dados de hidrodinâmica, onde foram identificadas ondas do tipo deslizante, que podem estar relacionadas ao baixo grau de inclinação do assoalho praial, 
pois não conseguem formar o tubo e quebrar. As ondas possuíam alturas em torno de $0,80 \mathrm{~m}$ e a velocidade de corrente registrada foi de $0,62 \mathrm{~m} / \mathrm{s}$. Desse modo, finaliza-se a compartimentação da paisagem de Ponta do Mel apresentando os aspectos da fisionomia da paisagem.

\section{Considerações finais}

Diante do exposto, puderam-se tecer algumas considerações finais acerca deste estudo. Desse modo, entende-se que cada vez mais os estudos voltados para o ambiente costeiro são considerados importantes no tocante ao planejamento e gestão destas áreas, uma vez que as mesmas possuem alta pressão demográfica. Diante disso, este trabalho se propôs a identificar e caracterizar os compartimentos de relevo presentes na paisagem da praia de Ponta do Mel.

Nesse sentido, mediante a análise da declividade do terreno, foram delimitadas duas unidades morfoesculturais: a planície praial e o tabuleiro costeiro semiárido, ambas separadas pelas falésias dos tabuleiros costeiros formados pelas rochas do Grupo Barreiras. Nessas unidades morfoesculturais foram identificados "tipos de formas de relevo" que foram prontamente caracterizados conforme a literatura disponível e as visitas de campo. Portanto, o estudo da compartimentação do relevo contribuiu para o entendimento da dinâmica dos processos presentes na praia de Ponta do Mel, localizada no município de Areia Branca no estado do Rio Grande do Norte.

\section{Bibliografia}

AB'SÁBER, Aziz Nacib. Um conceito de Geomorfologia serviço das pesquisas sobre o Quaternário. São Paulo: Instituto de Geografia da Universidade de São Paulo, 1969. Disponível em: < xa.yimg.com/kq/groups/14599993/294513207>. Acesso em: 04 jan. 2017.

BRASIL, Ministério de Minas e Energia. Secretaria-Geral. Projeto RADAMBRASIL. Folha SB 24/25 Jaguaribe/Natal; geologia, geomorfologia, pedologia, vegetação e uso potencial da terra. Rio de Janeiro, 744p., 1981.

CASSETI, Valter. $\quad$ Geomorfologia. $\quad$ [S.1.]: [2005]. Disponível em: <http://www.funape.org.br/geomorfologia/>. Acesso em: 15 mar 2012.

CHRISTOFOLETTI, Antônio. Geomorfologia. $2^{\circ}$ Ed. São Paulo: Blucher,1980.

Demek, J. Generalization of Geomorphological Maps. In: Progress Made in Geomorphology Mapping. Brno, IGU Commission on Applied Geomorphology, 1967.

DINIZ, M. T. M.; OLIVEIRA, G. P. Proposta de compartimentação em mesoescala para o litoral do nordeste brasileiro. Revista Brasileira de Geomorfologia, v. 17, p. 565-590, 2016. Disponível em: http://www.lsie.unb.br/rbg/index.php/rbg/article/view/844. Acesso: 09/03/2017.

GIANNINI, Paulo César Fonseca; ASSINE, Mário Luis; SAWAKUCHI, André Oliveira. Ambientes eólicos. In: SILVA, Augusto J. de C. L. P. da; ARAGÃO, Maria Alice N. F. de; MAGALHÃES, Antonio J. C. Ambiente de sedimentação siliciclástica do Brasil. São Paulo: Beca-BALL, 2008.

FARR, Tom G.; ROSEN, Paul A.; CARO, Edward et al. The shuttle radar topography mission. Reviews of Geophysics, $\mathrm{n}^{\circ}$ 45, jun. 2007. Disponível em: http://www2.jpl.nasa.gov/srtm/SRTM_paper.pdf Acesso: 07/03/2017.

IBGE, Instituto Brasileiro de Geografia e Estatística. Manual téenico de geomorfologia. Rio de Janeiro: IBGE, $2^{\mathrm{a}}$ ed. 2009. 
Mescejakov, J. P. Les concepts de morphostructure et de morphosculpture: un nouvel instrument de l'analyse géomorphologique. Annales de Geographie, n. 423, v. 77, set./out. 1968, p. 539-552.

MUEHE, D. ; NICOLODI, J. . Geomorfologia. In: Admilson Zamboni, João Luiz Nicolodi. (Org.). Macrodiagnóstico da Zona Costeira e Marinha do Brasil. Brasília: Ministério do Meio Ambiente, 2008. Disponível em: https://s3.amazonaws.com/tapajos/Macro/02_geomorfologia.pdf. Acesso: 04/01/2017.

ROSS, Jurandyr L. S.. Ecogeografia do Brasil: subsídios para Planejamento Ambiental. São Paulo: Oficina de Textos, 2009.

ROSS, Jurandyr L. S.. Geomorfologia: ambiente e planejamento. 9 9a $^{\mathrm{a}}$. São Paulo: Contexto, 2012.

ROSS, Jurandyr Luciano Sanches. "O Registro Cartográfico do Fatos Geomórficos e a Questão da Taxonomia do Relevo”. In: Revista do Departamento de Geografia - FFLCH-USP, nº 6, São Paulo, 2011.

TESSLER, Moysés Gonsalez; GOYA, Samara Cazzoli Y. Processos costeiros condicionantes do litoral brasileiro. Revista do Departamento de Geografia. n. 17, p 11-23. 2005.

VITAL, Helenice (Org.). Rio Grande do Norte. In: MUEHE, Dieter (Org.) Erosão e progradação do litoral brasileiro. Brasília: Ministério do Meio Ambiente, 2006, v. 1, p. 155-172. Disponível em: http://www.mma.gov.br/estruturas/sqa_sigercom/_arquivos/rn_erosao.pdf.

\section{Agradecimentos}

Os autores agradecem a Universidade Federal do Rio Grande do Norte (UFRN), ao Departamento do curso de Geografia (DGE) e a Coordenação de Aperfeiçoamento de Pessoal de Nível Superior (CAPES) pelo incentivo financeiro. 